\title{
Testing for Financial Spillovers in Calm and Turmoil Periods*
}

\author{
Jędrzej Białkowski*, Martin T. Bohl*****, and Dobromił Serwa ${ }^{* * *}$ \\ * Auckland University of Technology, Auckland \\ ** European University Viadrina, Frankfurt (Oder) \\ *** National Bank of Poland, Warsaw
}

July 2005, revised and resubmitted version

\begin{abstract}
In this paper, we investigate financial spillovers between stock markets during calm and turbulent times. We explicitly define financial spillovers and financial contagion in accordance with the economic literature and construct statistical models corresponding to these definitions in a Markov switching framework. Applying the new testing methodology based on transition matrices, we find that spillovers from the US stock market to the UK, Japanese, and German markets are more frequent when the latter markets are in the crisis regime. However, we reject the hypothesis of strong financial contagion from the US market to the other markets.
\end{abstract}

JEL Classification: F36, G12, G15

Keywords: financial spillovers, Markov switching models, capital markets, financial crisis

* We are grateful to Maria Carapeto, Ciner Cetin, Vasyl Golsnoy, Alain Monfort, Yarema Okhrin, Sunil Poshakwale, participants of the $3^{\text {rd }}$ INFINITI Conference in Dublin, the Financial Management Association Conference in Basel, the $3^{\text {rd }}$ Finance Conference of the Portuguese Finance Network in Lisbon, the European Summer Symposium in Financial Markets organized by CEPR in Gerzensee, and seminar participants at the European University Viadrina and the Warsaw University for valuable comments. Serwa acknowledges the financial support of the Foundation for Polish Science.

** Corresponding author: Martin T. Bohl, Faculty of Economics, European University Viadrina, Große Scharrnstraße 59, 15230 Frankfurt (Oder), Germany, Phone: ++ 493355534 2984, Fax: ++ 493355534 2959, E-mail: bohl@euv-frankfurt-o.de. 


\section{Introduction}

The importance of cross-market linkages and spillovers between international stock markets is well established. The literature on this issue allows to draw at least two main conclusions. First, the empirical studies find that the US stock market is the dominant capital market influencing other mature and developing stock markets (Eun and Shim (1989), Hamao, Masulis, and Ng (1990), Lin, Engle, and Ito (1994), Peiró, Quesada, and Uriel (1998), Ng (2000)). International stock markets are strongly correlated with the US market and past US stock returns affect present returns on other markets. Lagged spillovers are particularly interesting to investigate, because stock markets with some delay assimilate important news from other markets. The most likely reasons may be inefficiencies of international stock markets, different opening hours on those markets, and non-synchronous trading (Cheung and Ng (1996), Peiró, Quesada, and Uriel (1998)). Analyzing lead-lag effects enables investors to learn about the structure and direction of financial spillovers, which is important for effective portfolio allocation and risk management (e.g., Ang and Bekaert (2002, 2004)).

Second, investigations in the field of stock market linkages suggest that stock returns are more volatile and more correlated with each other during turbulent periods compared to tranquil periods (King and Wadhwani (1990), Karolyi and Stulz (1996), Longin and Solnik (2001), Forbes and Rigobon (2002)). A rising positive correlation may suggest a decrease of capital diversification opportunities across markets during financial crises (Ang and Bekaert (2002), Bekaert and Harvey (2003)). The differences in financial spillovers during calm and turmoil periods are of special interest to agents who want to learn about the chance of having a crisis at the home market today, when there was a negative shock to another market yesterday. International investors can adjust their portfolio strategies to a changing structure of spillovers in different regimes. Moreover, financial market regulators are concerned about the vulnerability of home capital markets to international crises. 
Despite the importance of both aspects only a few studies investigate changes in leadlag effects of financial spillovers during calm periods and financial crises. The scarce findings suggest that spillovers from one market to other markets are found to be stronger when the former market is hit by some negative shock (Malliaris and Urrutia (1992), Sola, Spagnolo, and Spagnolo (2002), Chen, Chiang, and So (2003), Climent and Meneu (2003), Sander and Kleimeier (2003)). This paper develops a Markov-switching framework for testing the lead-lag dependences that are allowed to be asymmetric with respect to stock markets' states of calm or crisis.

For example, our testing framework enables us to examine whether stock markets undergoing financial distress are still vulnerable to spillovers from other markets. Finding an answer to this issue may help in analyzing sources of financial crises. Stronger spillovers to turmoil stock markets could point to contagion as the main source of crises, while weaker spillovers could suggest an individual character of financial distress.

Most studies analyzing spillovers between stock markets during tranquil and crisis times do not take into account that the two analyzed markets can be in two different regimes of crisis or calm, i.e., the stock market following the other market can be in the state of crisis independently of the state of the leading market. Another drawback of some studies is the ad hoc method used to identify crisis and calm periods (e.g., Malliaris and Urrutia (1992), Forbes and Rigobon (2002), Dungey and Zhumabekova (2001)). For example, in Chen, Chiang, and So (2003) the two regimes are explicitly defined as past stock returns exceeding (or falling below) an estimated threshold level. Moreover, earlier studies usually concentrate on specific events.

In this paper, we consider spillover effects from the US stock market to three major markets in Japan, the UK, and Germany over the period from 1984 to 2003 as well as subsamples. We compare spillover effects during tranquil and turbulent periods and address the 
problems expressed above by extending the Markov switching model proposed by Phillips (1991). Phillips developed a bivariate Markov switching model to evaluate the transmission of business cycles between countries. Sola, Spagnolo, and Spagnolo (2002) applied this approach in the framework of financial markets to test their specific hypothesis of contagion across stock markets during the Asian crisis in 1997. Edwards and Susmel (2001) added lagged returns and conditional autoregressive heteroscedasticity into the model specification and investigated tests of independence and co-movements between international emerging stock markets in 1990s. More recently, Białkowski and Serwa (2005) proposed tests for causality between stock markets in a Markov switching framework.

We construct a model of stock index returns for two markets analogous to the one proposed by Sola, Spagnolo, and Spagnolo (2002) and develop a test to investigate the hypotheses that, first, one market leads the other in both turmoil and tranquil periods and, second, one market leads the other only when the latter is already in a turmoil (calm) period. In this way we extend the methodology proposed by Edwards and Susmel (2001), Sola, Spangolo, and Spagnolo (2002), and Białkowski and Serwa (2005), used to test financial contagion, causality, and independence by applying tests for asymmetric financial spillovers in a Markov switching framework (see also Ravn and Sola (1995), Hamilton and Lin (1996), Psaradakis, Ravn, and Sola (2004)).

Our testing procedure has several advantages over other approaches to analyze the transmission of spillovers across stock markets. First, for each stock market it differentiates between calm and turbulent regimes. Thus, the method allows for a measurement of spillovers depending on the state of the market. The empirical literature suggests that multi-regime switching models of stock returns perform better than one-regime models (Cecchetti, Lam, and Mark (1990), Turner, Stratz, and Nelson (1990), Rydén, Teräsvirta, and Åsbrink (1998), Ang and Bekaert (2002)). Second, our procedure does not require an ad hoc identification of periods 
to examine spillovers between stock markets. Instead it estimates the probabilities of being in the crisis in a joint framework with all parameters of the model. Third, correlation and regression measures often fail to explore non-linear relations between variables. We offer a test on cross-market spillovers which does not depend on a specific linear or non-linear structure of linkages between stock returns. Fourth, Sola, Spagnolo, and Spagnolo (2002) provide a test of extreme spillovers, which they call a test of contagion. Our test is more flexible than the one applied there, since it examines a wider range of possible spillovers between the stock markets.

Finally, as an additional characteristics, most of the studies do not explicitly define spillovers between stock markets. In this paper, we provide a definition of one market leading other market that allows for distinguishing between lead-lag relations in calm and turbulent periods. This definition is consistent with the notion of causality, while in the context of financial crises it suits well the concept of contagion. To distinguish between extreme cases of spillovers we provide explicit definitions of independence (no spillovers) and contagion, which are in line with Sola, Spagnolo, and Spagnolo (2002), and compare the empirical results for tests based on those definitions.

The remainder of this paper is organized as follows. In the next section we describe the model based on the idea of Phillips (1991) to estimate stock index returns on two markets. Section 3 discusses our definitions of financial spillovers and discusses the tests for dependencies between the markets. Data and empirical results on spillovers from the US stock market to the Japanese, British, and German stock market are presented in section 4. Section 5 summarizes and concludes.

\section{Modeling index returns on two markets}

Our econometrical starting point is a Markov switching model of index returns on two markets. Let $Z$ be the vector $[X, Y]^{\prime}$, where $X=\left\{x_{t}, t \in N\right\}$ and $Y=\left\{y_{t}, t \in N\right\}$ are the two 
time series that can be interpreted as stock market index returns on two separate markets. Both index returns are allowed to enter one of the two complementary states of "crisis" and "calm" periods. Using all four combinations of these states we construct a Markov process with four regimes and we use the index $s$ to denote these regimes. " $X$ and $Y$ are in the calm states" defines the first regime $(s=1)$. " $X$ is in the calm state and $Y$ is in the crisis state" denotes the second one $(s=2)$. The third regime indicates that " $X$ is in the crisis state and $Y$ is in the calm state" $(s=3)$. " $X$ and $Y$ are in the crisis states" defines the fourth regime $(s=4)$.

At each point in time, the state $s$ is determined by an unobservable Markov chain. The dynamics of the Markov chain are described by a $4 \times 4$ transition matrix $P$ :

$$
P=\left(\begin{array}{llll}
p_{11} & p_{12} & p_{13} & p_{14} \\
p_{21} & p_{22} & p_{23} & p_{24} \\
p_{31} & p_{32} & p_{33} & p_{34} \\
p_{41} & p_{42} & p_{43} & p_{44}
\end{array}\right)
$$

where $p_{i j}$ denotes the probability of changing the state from $i$ to $j$. Assume that the $2 \times 1$ vector $z_{t}=\left[x_{t}, y_{t}\right]^{\prime}$ is driven by the four-state regime switching process:

$$
z_{t}=\mu_{s}+\Theta_{s} u_{t}
$$

where $u_{t}$ is a Gaussian process with zero mean and positive-definite covariance matrix $\Sigma$. The vector $z_{t}$ is generated by the mixture of normal distributions with the mean $\mu_{s}$ and the covariance matrix $\Sigma_{s}$, both depending on the state $s$ :

$$
z_{t} \mid\left(s_{t}=s\right) \sim N\left(\mu_{s}, \Sigma_{s}\right)
$$

and:

$$
\Sigma_{s}=\Theta_{s}^{\prime} \Sigma \Theta_{s}
$$

for $s=1,2,3,4$. Thus, the model is called a (four-state) Markov switching mixture of normal distributions and it consists of 32 independent parameters, namely two parameters of means for each state, three independent parameters from $\Sigma_{s}$ for each state, and twelve independent 
parameters from the transition matrix $P$. In this model no constraints are imposed on the parameters of means, variances, correlations, and parameters from the transition matrix $P$.

Economists highlight the significance of changes in return volatility during crisis periods. The high variance of index returns characterizes turmoil periods and the low variance characterizes tranquil periods. Additionally, the correlation coefficients between returns on different markets tend to increase when one of the markets enters the crisis regime (e.g. King and Wadhwani (1990), Karolyi and Stulz (1996), Longin and Solnik (2001), Forbes and Rigobon (2002)). However, some authors define crisis regimes as low average returns observed over longer periods or appearance of unusually low returns (Longin and Solnik (2001), Chen, Chiang, and So (2003), Mishkin and White (2003), Hartmann, Straetmans, and de Vries (2004)).

Therefore, in our paper we highlight the importance of changes in the variance and correlation by allowing them to take different values in all four regimes. Moreover, we restrict the parameter space by assuming that the mean of returns on each market switches between its high and low value depending on the state of this market. The high value of mean describes a market in the calm regime and the low value of mean describes a market in the crisis regime. We expect low mean returns, high variances, and high correlation when both markets are in the crisis regime and high means, low variances, and low correlation when both markets are in the tranquil regime. The parameter space for means, variances, and correlations between returns on the two markets is defined as follows:

$$
\begin{aligned}
& \mu=\left\{\mu_{s=1}=\left[\begin{array}{c}
\mu_{T}^{X} \\
\mu_{T}^{Y}
\end{array}\right], \mu_{s=2}=\left[\begin{array}{c}
\mu_{T}^{X} \\
\mu_{C}^{Y}
\end{array}\right], \mu_{s=3}=\left[\begin{array}{c}
\mu_{C}^{X} \\
\mu_{T}^{Y}
\end{array}\right], \mu_{s=4}=\left[\begin{array}{c}
\mu_{C}^{X} \\
\mu_{C}^{Y}
\end{array}\right]\right\}, \\
& \sigma=\left\{\sigma_{s=1}=\left[\begin{array}{c}
\sigma_{T_{1}}^{X} \\
\sigma_{T_{1}}^{Y}
\end{array}\right], \sigma_{s=2}=\left[\begin{array}{c}
\sigma_{T_{2}}^{X} \\
\sigma_{C_{1}}^{Y}
\end{array}\right], \sigma_{s=3}=\left[\begin{array}{c}
\sigma_{C_{1}}^{X} \\
\sigma_{T_{2}}^{Y}
\end{array}\right], \sigma_{s=4}=\left[\begin{array}{c}
\sigma_{C_{2}}^{X} \\
\sigma_{C_{2}}^{Y}
\end{array}\right]\right\},
\end{aligned}
$$

and: 


$$
\rho=\left\{\rho_{s=1}=\rho_{T T}^{X Y}, \rho_{s=2}=\rho_{T C}^{X Y}, \rho_{s=3}=\rho_{C T}^{X Y}, \rho_{s=4}=\rho_{C C}^{X Y}\right\}
$$

Symbols $T, T_{1}$, and $T_{2}$ denote the state of tranquility on the respective market (the numbers are to distinguish between different values of a particular parameter in different regimes). Symbols $C, C_{1}$, and $C_{2}$ denote the crisis state. The transition matrix remains unconstrained, therefore we call this model a "general" or "unconstrained" model.

In order to examine how our model fits the data we use several tests proposed by Breunig, Najarian, and Pagan (2003). We compare the means, variances, and peaks of the empirical distributions of the original data and the data simulated from our model. Additionally, we investigate a "leverage effect" for both sets of data. The leverage effect is a common feature of stock returns indicating higher volatility of returns when past returns are negative (e.g. Black (1976), Engle and $\mathrm{Ng}(1993)$ ). We find that our models are consistent with the original data in all cases and for all tests. Detailed results are presented in Appendix.

\section{Independence, Spillovers, and Contagion}

In addition to the Markov switching model we need definitions of regimeindependence, contagion and spillovers. These definitions enable us to assess the strength of shock transmission between the markets during stable and turmoil periods. Moreover, the definitions provide us the basis to distinguish between spillovers when one of the markets is in the crisis or in the calm state. We also describe the tests for no spillovers and contagion and propose our testing procedures to analyze the hypotheses of, first, one market leading the other during calm periods and, second, one market leading the other during crisis periods. The null hypothesis is that a spillover effect exists between the markets in both periods. 


\subsection{Two extremes: contagion and independence}

There exist several definitions of contagion and methods to test them. The definitions presented in this paper are strongly related to the original description of contagion discussed in Eichengreen, Rose, and Wyplosz (1996) (Pericoli and Sbracia (2003), Hartmann, Straetmans, and de Vries (2004), and Fontaine (2005) among others). Contagion is defined there as "a significant increase in the probability of a crisis in one country, conditional on a crisis occurring in another country". Sola, Spagnolo, and Spagnolo (2002) suggested an extreme case of this definition, where the probability of having a crisis at home equals one if the crisis hits another market. We explore their methodology (Definitions 1 and 2) and propose a modest alternative that suits more closely the description presented above (Definition 3).

Another branch of studies explore changes in the structure of inter-market linkages, i.e. "shift-contagion" hypothesis (Forbes and Rigobon (2001)). They usually analyze changes in the correlation of international stock returns (e.g. King and Wadhawani (1990), Forbes and Rigobon (2002), Pericoli and Sbracia (2003)) or define contagion as excessive spillovers from one market into another during turbulent periods beyond structural linkages between these markets (Rigobon (2003)). Although we concentrate on the tests of financial spillovers based on the probability measures, our modeling framework provides evidence on changing correlation of stock returns on different markets in stable and turbulent regimes.

Yet one more group of investigations focuses on coincidence of extreme return shocks across countries as evidence of contagion (Longin and Solnik (2001), Bae, Karolyi, and Stulz (2003), Hartman, Streatman, and de Vries (2004)). Bae, Karolyi, and Stulz express the concern that correlations which give equal weight to small and large shocks are not appropriate for an evaluation of the impact of large (possibly negative) returns. Similarly to their study, our model allows to evaluate the likelihood of joint occurrence of low and large returns on 
different markets. The low and large returns are distinguished here using multiple regimes and changes in the correlation structure are conditional on these regimes.

Other strategies to empirically study contagion include testing whether markets respond to news from other markets, analyzing the significance, size, and changes of coefficients in (limited dependent variable) regressions, VAR, and GARCH models, and studying intermarket correlation after controlling for market fundamentals. Many definitions of contagion and their applications are surveyed in Dornbusch, Park, and Claessens (2000), Claessens and Forbes (2001), Billio and Pelizzon (2003), Karolyi (2003), Moser (2003), Pericoli and Sbracia (2003), and on World Bank web pages.

Definition 1. Let $Z=\left[\begin{array}{ll}X & Y\end{array}\right]^{\prime}$ be described by the Markov switching model introduced above. $Y$ is said to be "regime-independent" of $X$ if the event that $Y$ enters the state $i$ at time $t$ is independent of the present and past states of $X$, where $i$ is the crisis or calm regime in our Markov switching model.

Sola, Spagnolo, and Spangolo (2002) employ the definition of regime-independence of $X$ and $Y$ to test for contagious spillovers between financial markets. In case $Y$ and $X$ are regime-independent the following restrictions are imposed on the transition matrix $P$ :

$$
P=\left(\begin{array}{cccc}
\pi_{T T}^{X} \pi_{T T}^{Y} & \pi_{T T}^{X}\left(1-\pi_{T T}^{Y}\right) & \left(1-\pi_{T T}^{X}\right) \pi_{T T}^{Y} & \left(1-\pi_{T T}^{X}\right)\left(1-\pi_{T T}^{Y}\right) \\
\pi_{T T}^{X}\left(1-\pi_{C C}^{Y}\right) & \pi_{T T}^{X} \pi_{C C}^{Y} & \left(1-\pi_{T T}^{X}\right)\left(1-\pi_{C C}^{Y}\right) & \left(1-\pi_{T T}^{X}\right) \pi_{C C}^{Y} \\
\left(1-\pi_{C C}^{X}\right) \pi_{T T}^{Y} & \left(1-\pi_{C C}^{X}\right)\left(1-\pi_{T T}^{Y}\right) & \pi_{C C}^{X} \pi_{T T}^{Y} & \pi_{C C}^{X}\left(1-\pi_{T T}^{Y}\right) \\
\left(1-\pi_{C C}^{X}\right)\left(1-\pi_{C C}^{Y}\right) & \left(1-\pi_{C C}^{X}\right) \pi_{C C}^{Y} & \pi_{C C}^{X}\left(1-\pi_{C C}^{Y}\right) & \pi_{C C}^{X} \pi_{C C}^{Y}
\end{array}\right),
$$

where $\pi_{i j}^{Q}$ denotes the probability of entering the state $j$ by the time series $Q$ at time $t$ when it was in the state $i$ at time $t-1 . Q \in\{X, Y\}, i, j \in\{T, C\}$, and $T$ and $C$ denote the calm and crisis regimes, respectively. It should be noted that regime-independence does not imply independence of $X$ and $Y$, since they are still allowed to be correlated with each other. 
Definition 2. Contagion from $X$ to $Y$ is present when the probability that $Y$ enters the state $i$ at time $t$ conditional on the information that $X$ was in this state at time $t-1$ is equal one, where $i$ denotes the crisis or calm regime in our Markov switching model.

According to this definition the stock index return $Y$ has to enter a specific regime, e.g. the crisis regime, if the stock index return $X$ was there one period earlier. Thus, the sum of conditional probabilities $p_{11}$ and $p_{13}$ in the transition matrix $P$ can be formulated as:

$$
p_{11}+p_{13}=1
$$

Calm and crisis are complementary events and we can express the sum of the probabilities as:

$$
p_{11}+p_{13}=\operatorname{Pr}\left(Y_{t} \text { in calm } \mid X_{t-1} \text { in calm and } Y_{t-1} \text { in calm }\right)
$$

because:

$$
\begin{aligned}
& p_{11}=\operatorname{Pr}\left(X_{t} \text { in calm and } Y_{t} \text { in calm } \mid X_{t-1} \text { in calm and } Y_{t-1} \text { in calm }\right) \\
& p_{13}=\operatorname{Pr}\left(X_{t} \text { in crisis and } Y_{t} \text { in calm } \mid X_{t-1} \text { in calm and } Y_{t-1} \text { in calm }\right) .
\end{aligned}
$$

Analogously, the other constraints on the transition matrix are:

$$
\begin{aligned}
& p_{21}+p_{23}=1, \\
& p_{32}+p_{34}=1, \\
& p_{42}+p_{44}=1
\end{aligned}
$$

and the transition matrix $P$ takes on the form:

$$
P=\left(\begin{array}{cccc}
p_{11} & 0 & 1-p_{11} & 0 \\
p_{21} & 0 & 1-p_{21} & 0 \\
0 & p_{32} & 0 & 1-p_{32} \\
0 & p_{42} & 0 & 1-p_{42}
\end{array}\right)
$$

Our definition of contagion is a less restrictive version of the one put forward by Sola, Spagnolo, and Spagnolo (2002) and is inspired by the work of Phillips (1991). Sola, Spagnolo, and Spagnolo set additional constraints assuming that $p_{11}=p_{21}$ and $p_{32}=p_{42}$, i.e. the probability that both markets, $X$ and $Y$, enter the crisis or the calm regime does no depend on 
the regime of $Y$ in the previous period. Thus, the past realizations of $Y$ do not influence $X$ when there is contagion from $X$ to $Y$. Such an additional restriction has been criticized in the financial contagion literature due to the possibility of an estimation bias coming from overlooking the bi-directional transmission of shocks between the markets (Forbes and Rigobon (2002), Billio and Pelizzon (2003), Moser (2003), Rigobon (2003)).

Additionally, the idea of contagion is usually associated with financial crises spilling over from one market to other markets. One can expect that one market infects the other market only when it is in the crisis regime. Such a definition of "contagion in the crisis regime" corresponds to the transition matrix:

$$
P=\left(\begin{array}{cccc}
p_{11} & p_{12} & p_{13} & p_{14} \\
p_{21} & p_{22} & p_{23} & p_{24} \\
0 & p_{32} & 0 & 1-p_{32} \\
0 & p_{42} & 0 & 1-p_{42}
\end{array}\right)
$$

The important characteristics of these definitions are identification of direction of contagion and financial spillovers from one market to another occurring with a lag, which allows for identification of delays in information or capital flows between markets (Climent and Meneu (2003), Sander and Kleimeier (2003)).

\subsection{Identifying spillovers}

Our contagion definitions in the spirit of Sola, Spagnolo, and Spagnolo (2002) are very restrictive. Even rejecting them does not imply that one market does not lead the other (Ravn and Sola (1995)). Therefore, we propose a weaker form of inter-market dependency that fits well the idea of increased probability of a crisis at home, given the crisis occurred abroad and is based on the notion of financial spillovers and causality (e.g., Geweke (1984)).

In this study, we use the expressions "spillovers" and "causality" interchangeably, because the original idea of Granger $(1969,1980)$ causality is translated into the Markov 
switching framework (Białkowski and Serwa (2005)) and causality is interpreted as evidence of financial spillovers between markets (Hamao, Masulis, and $\mathrm{Ng}$ (1990), Climent and Meneu (2003), among others). In contrast to previous studies exploring causality in mean (e.g., Malliaris and Urrutia (1992)) or causality in volatility (Cheung and $\mathrm{Ng}$ (1996)), this approach investigates causality in probability of entering the specific state by market $Y$, conditional on past information from markets $X$ and $Y$.

Definition 3. $X$ leads $Y$ by one period if the magnitude of the probability that $Y$ enters the state $i$ at time $t$ depends on whether $X$ was in the state $j$ at time $t-1$, where $i$ and $j$ are allowed to be the crisis or calm regimes in our Markov switching model.

We understand Granger causality from $X$ to $Y$ as evidence of the difference in conditional probabilities of $Y$ entering the state $i$, when $X$ was in the calm state or in the crisis state at time $t-1$, respectively. The case of $X$ leading $Y$ is interpreted in the context of inter-market linkages as a presence of financial spillovers from one market to the other. For example, the definition of spillovers comprises the situation when the probability of one market entering the crisis regime depends not only on whether this market was in the state of crisis one period earlier, but also on whether the other market was there in the previous period:

$$
\begin{aligned}
& \operatorname{Pr}\left(Y_{t} \text { in crisis } \mid X_{t-1} \text { in crisis and } Y_{t-1} \text { in crisis }\right) \\
& \qquad \quad \operatorname{Pr}\left(Y_{t} \text { in crisis } \mid X_{t-1} \text { in calm and } Y_{t-1} \text { in crisis }\right),
\end{aligned}
$$

which can be expressed in terms of parameters from the transition matrix $P$ as:

$$
p_{22}+p_{24} \neq p_{42}+p_{44}
$$

Analogously, the following inequalities must be valid if $X$ leads $Y$ in all regimes:

$$
\begin{aligned}
& p_{11}+p_{13} \neq p_{31}+p_{33}, \\
& p_{21}+p_{23} \neq p_{41}+p_{43}, \\
& p_{12}+p_{14} \neq p_{32}+p_{34},
\end{aligned}
$$




$$
p_{22}+p_{24} \neq p_{42}+p_{44}
$$

If one assumes that no spillovers exist between the markets in any regimes, the inequalities (18) to (21) become equalities and then the transition matrix $P$ is defined as:

$$
P=\left(\begin{array}{cccc}
p_{11} & p_{12} & p_{13} & p_{14} \\
p_{21} & p_{42}+p_{44}-p_{24} & p_{41}+p_{43}-p_{21} & p_{24} \\
p_{31} & p_{12}+p_{14}-p_{34} & p_{11}+p_{13}-p_{31} & p_{34} \\
p_{41} & p_{42} & p_{43} & p_{44}
\end{array}\right)
$$

It can be shown that the constraint $p_{22}=p_{42}+p_{44}-p_{24}$ is equivalent to $p_{23}=p_{41}+p_{43}-p_{21}$ and that the constraint $p_{32}=p_{12}+p_{14}-p_{34}$ is equivalent to $p_{33}=p_{11}+p_{13}-p_{31}$. Therefore, the parameters $p_{23}$ and $p_{33}$ can be set unconstrained in the estimation process.

Additionally, one can assume that no spillovers from $X$ to $Y$ will be present at time $t+1$ in case $Y$ is in the crisis state at time $t$. For example, the influence of the US market on the Japanese market could strongly diminish, when the Japanese market is hit by the strong internal crisis. In this case the transition matrix $P$ will be defined as follows:

$$
P=\left(\begin{array}{cccc}
p_{11} & p_{12} & p_{13} & p_{14} \\
p_{21} & p_{22} & p_{23} & p_{24} \\
p_{31} & p_{12}+p_{14}-p_{34} & p_{11}+p_{13}-p_{31} & p_{34} \\
p_{41} & p_{42} & p_{43} & p_{44}
\end{array}\right) .
$$

Alternatively, the opposite hypothesis of no spillovers from $X$ to $Y$ when $Y$ is in the calm regime may be denoted by:

$$
P=\left(\begin{array}{cccc}
p_{11} & p_{12} & p_{13} & p_{14} \\
p_{21} & p_{42}+p_{44}-p_{24} & p_{41}+p_{43}-p_{21} & p_{24} \\
p_{31} & p_{32} & p_{33} & p_{34} \\
p_{41} & p_{42} & p_{43} & p_{44}
\end{array}\right) .
$$

Generally, the Markov switching approach fits well the idea of investigating spillovers and contagion between the markets during stable and turmoil periods. Analyzing differences between spillovers to calm and crisis markets is made possible by setting the suitable 
restrictions on parameters from the transition matrix. Thus, one does not need to assume any specific linear or nonlinear structure of spillovers between the markets, like in autoregressive and ARCH models, since both contagion and spillovers are introduced directly through the probability measures.

\subsection{Testing framework}

The definitions introduced above are helpful in building tests of financial contagion, spillovers, and independence between the markets. The general model, described by the equations (1) to (5), imposes no restrictions on the transition matrix $P$ and assumes financial spillovers in both stable and turbulent regimes. It can be estimated using the standard Expectation-Maximization (EM) algorithm, similarly to Hamilton (1989, 1990). A similar technique is applied to estimate the contagion models, employing equations (2) to (5) and transition matrices (14) and (15). The models assuming regime-independence (no spillovers), no spillovers in crisis periods, no spillovers in calm periods, and no spillovers in any regime use the transition matrices (6), (23), (24), and (22), respectively.

The models with constrained transition matrices are estimated using an algorithm analogous to the one described by Phillips (1991). Details are available upon request. The loglikelihood values corresponding to the estimates are denoted by $L_{\text {SPILLOVERS }}$ for the general model with no constraint on the transition matrix $P, L_{\text {INDEPENDENCE }}$ for the regimeindependence model, $L_{\text {CONTAGION }}$ for the contagion model, $L_{\text {CONTAGION IN CRISIS }}$ for the "contagion during crises" model, and $L_{\text {NO SPILLOVERS }}$ L LO SPILLOVERS IN CRISIS $L_{N O}$ SPILOVERS IN CALM for the no-spillover models with the transition matrices (22), (23), and (24), respectively.

Figure 1 about here 
We describe now our testing procedure used to explore possible interdependencies between capital markets. In Figure 1 the testing hypotheses are ordered in the general-tospecific sequence. Exceptions are Hypotheses 3a and 3b, which are not nested in Hypothesis 2. We start with testing the null hypothesis assuming that there is contagion from $X$ to $Y$ when both markets are in the crisis regime (Hypothesis 1) against the alternative of no contagion. Under the null hypothesis, the likelihood ratio statistic:

$$
L R=2\left(L_{\text {SPILLOVERS }}-L_{\text {CONTAGION IN CRISIS }}\right) \sim \chi^{2}(4)
$$

has the standard asymptotic $\chi^{2}$ distribution with four degrees of freedom. If the null hypothesis can be accepted, we continue with testing the hypothesis that contagion exists in both calm and crisis regimes (Hypothesis 2). We use the likelihood ratio statistic:

$$
L R=2\left(L_{\text {SPILLOVERS }}-L_{\text {CONTAGION }}\right) \sim \chi^{2}(8),
$$

which has the asymptotic $\chi^{2}$ distribution with eight degrees of freedom (Sola, Spagnolo, and Spagnolo (2002)).

If the Hypothesis 1 is rejected then no contagion exists in any regimes and we follow the procedure by analyzing the hypothesis that no spillovers from $X$ to $Y$ are present in cases $Y$ was in the calm regime at time $t-1$ (Hypothesis 3a). Alternatively, one can test the hypothesis of no spillovers to $Y$ in case $Y$ was in the crisis regime at time $t-1$ (Hypothesis 3b). The respective statistics are:

$$
L R=2\left(L_{\text {SPILLOVERS }}-L_{\text {NO SPILLOVERS IN CALM }}\right) \sim \chi^{2}(1)
$$

and:

$$
L R=2\left(L_{\text {SPILLOVERS }}-L_{\text {NO SPILLOVERS IN CRISIS }}\right) \sim \chi^{2}(1)
$$

If the both hypotheses are rejected, we conclude that financial spillovers from $X$ to $Y$ are present in both regimes (Hypothesis 6) and finish the procedure here. When one of the above 
hypotheses, $3 \mathrm{a}$ or $3 \mathrm{~b}$, is accepted, we utilize the following statistic to test the Hypothesis 4 of no spillovers between the markets in any regime:

$$
L R=2\left(L_{\text {SPILLOVERS }}-L_{\text {NO SPILLOVERS }}\right) \sim \chi^{2}(2) .
$$

When this hypothesis is accepted, we conclude that $X$ does not lead $Y$ by one period, but some interdependencies between stock index returns on both markets, which take place simultaneously (e.g. on the same day) may still be present. The probability of one market entering the crisis or calm regime may still depend on the regime that the other market will enter collaterally. To rule out such dependencies between the markets we test the hypothesis that markets are regime-independent (Hypothesis 5) by applying the following test statistic:

$$
L R=2\left(L_{\text {SPILLOVERS }}-L_{\text {INDEPENDENCE }}\right) \sim \chi^{2}(12) .
$$

If this hypothesis is accepted, the markets enter any regimes independently of other markets (Phillips (1991), Sola, Spangolo, and Spagnolo (2002)). The flexibility of the test rests on the fact that both markets are still allowed to be correlated in each regime. This characteristic can almost always be observed between financial markets (e.g., Forbes and Rigobon (2002)).

The Markov switching models, employed by testing different hypotheses, differ only in parameters of the transition matrix $P$. In this way we avoid the problem of existence of some nuisance parameters that would be unidentified under the null hypotheses - a typical obstacle in testing multi-regime models. Therefore, our likelihood ratio statistics have their standard asymptotic distributions, as in Phillips (1991), Ravn and Sola (1995), and Sola, Spagnolo, and Spagnolo (2002).

The testing procedure outlined here is not meant to compare spillovers between the markets depending on the regime of the leading market. The important feature of the hypotheses $3 \mathrm{a}, 3 \mathrm{~b}$, and 4 is that they enable us to analyze the question raised in the introduction, whether markets undergoing a financial distress are more or less vulnerable to spillovers from other markets. 


\section{Data and Empirical Results}

In this section, we report the results obtained from the testing methodology outlined above and present the calculated probabilities of a crisis on each market when there was a crisis on the US market one day earlier. In our analysis we employed the standard capital market indices from the four largest markets in the world. The S\&P 500 index represents the US market, the NIKKEI 225 is the index for the Japanese market, the FTSE 100 index corresponds to the UK market, and the DAX stands for the German index. The index returns are computed as first differences of logged daily closing prices from the four markets and cover the period from April 3, 1984 to May 30, 2003, which corresponds to 4423 observations.

As argued in the introduction, the US is believed to be the dominating market leading other stock markets independently of crisis and calm periods. Therefore, in the empirical analysis we concentrate on spillovers from the US market to the other three markets, although the model applied here complies bi-directional interdependencies. Using the proposed algorithm, we check whether the structure of dependencies of the British, German, and Japanese markets on the US market should be called spillovers or rather contagion. In addition, we test for possible changes in the linkages between the markets during turbulent and calm periods. Next, we present the final models obtained from the testing procedure and compute the probabilities of the potential turmoil on the British, German, and Japanese market individually conditional on the information that the US market was in the turmoil regime one period earlier.

In order to analyze whether linkages between the markets have varied over time independently of crisis and calm regimes, we additionally calculate all tests for three nonoverlapping sub-periods from April 3, 1984 to December 28, 1988, from January 4, 1989 to December 29, 1995, and from January 4, 1996 to May 30, 2003. The 1996 - 2003 sub-sample 
is characterized by a considerable high variance of index returns on all markets in comparison to previous periods, which could eventually influence the general results. We also divide the rest of the time series into the two sub-periods, where the $1989-1995$ interval is a relatively stable period and the $1984-1988$ period comprises the great crash of the 1987 that has been found to influence spillovers from the US to other markets (Malliaris and Urrutia (1992)).

Each model of the bilateral linkages between the US market and the other market is estimated in seven different versions. The first version corresponds to the general model with no restrictions on the transition matrix $P$, which allows for potential spillovers between the markets. The second model assumes that both markets are regime-independent from each other and the third one assumes no spillovers from the US market to the other market. The fourth model is estimated under the constraint that no spillovers exist when the dependent market is in the state of crisis and the fifth one assumes no spillovers when the dependent market is in the calm regime. The sixth and seventh cases are the models of contagion from the US to the other market and contagion only in the crisis periods, respectively.

In Table 1 the log-likelihood values from the estimated models are presented. The general model has the highest likelihood value for each pair of markets, since all other models are restricted versions of the general model. Additionally, the "regime-independence" models are special cases of the "no-spillovers" models, which in turn set additional constraints in comparison to the "no-spillovers in crisis" and "no-spillovers in calm periods" models. Finally, the both "contagion" models are restricted forms of the general model.

Table 1 about here

To distinguish which models are statistically justified and which are too restrictive we employ the likelihood ratio statistics described in the previous section. All the results from our 
testing procedure are presented in Table 2. For all pairs of markets, the hypotheses of contagion and a weaker hypothesis of contagion in the crisis regime is rejected, which corresponds to the result of Sola, Spagnolo, and Spangolo (2002). Hence, we continue the procedure by testing the null hypotheses of no spillovers in crisis periods, no spillovers in calm periods, and no spillovers in any regimes. All of them are also rejected and we interpret these results as existence of spillovers from the US to the Japanese, British, and German markets independently of whether these latter markets are in crisis or calm regimes.

Table 2 about here

It is interesting to note that the test statistics for the hypothesis of no spillovers during crises always have higher values than the statistics for the hypothesis of no spillovers during calm periods. Assuming no spillovers when the Japanese, British, and German markets are in crisis regimes would be a more likely choice than assuming no spillovers in calm regimes. However, these both hypotheses, and models, are rejected as too restrictive. Finally, the regime-independence is also rejected in all cases, which confirms that some interdependencies are present between the US and other markets.

One explanation for the evidence of spillovers but no evidence of contagion could be that most information from the US markets spills over to the British and German markets already on the same day due to nonsynchronous, overlapping trading hours on the US and European stock exchanges. Thus, as a robustness check, we calculated all tests for these stock markets with 24-hour stock returns, synchronized by using index values at 4 p.m. Greenwich Mean Time for each day. The data are obtained from the Datastream database for the period from August 30, 1990 to May 30, 2003. We received qualitatively the same results. The empirical findings are not reported but available on request. 
According to our results the best models of dependencies between the markets are the general unconstrained models allowing for spillovers in all regimes, but not restricting these spillovers only to contagion effects. We present the parameters of these final models in Table 3. It is important that all the models match the main empirical patterns found on international capital markets. First, the regime with low average index returns on both markets is characterized by higher volatility of index returns than the regime with both markets in calm periods. It is interesting to note that the highest (lowest) volatilities are always obtained in the same regime for both markets. Moreover, in each model the regime with highest volatilities on the two markets is the one with one market in the state of crisis and the other market in the state of calm.

Table 3 about here

Second, when both markets are in the crisis regime they become more correlated with each other than when they are in their calm regimes (e.g., Longin and Solnik (2001), Forbes and Rigobon (2002)). Finally, from the elements of the transition matrices it can be observed that the probability of staying in the same regime is always highest for all regimes and all estimated models. This result can be interpreted as evidence of persistence of high (low) volatility in stock market index returns in line with the well-known characteristics of autoregressive conditional heteroscedasticity in stock index returns (e.g., Rydén, Teräsvirta, and Åsbrink (1998)). Against the background of these findings ARCH effects can at least partially be explained by the evidence of persistent calm and turbulent regimes. Significant causality from the US market implies that the persistence of the US market volatility also affects the intensity of ARCH effects on other developed markets. 
Moreover, comparing the estimated transition matrices in Table 3 with constraints proposed in equations (14) and (15) leads to the conclusion that the high values of the parameters $p_{22}$ and $p_{33}$, which can be interpreted as indicators of persistence of the states 2 and 3, are main reasons for rejecting both contagion hypotheses in the spirit of Sola, Spagnolo, and Spagnolo (2002).

Our results, suggesting that the spillovers hypothesis is valid, are consistent with the literature defining contagion as an increase in the probability of having a crisis at home when there is a crisis on the other market. Eichengreen, Rose, and Wyplosz (1996) and Hartmann, Streatmans, and de Vries (2004) also find evidence of contagion when they apply the same definition of contagion. The evidence of causality from the US market to other developed markets, interpreted as inter-market financial spillovers, is in line with other empirical studies finding causation effects in returns and volatility from the US market (Eun and Shim (1989), Hamao, Masulis, and Ng (1990), Malliaris and Urrutia (1992), Lin, Engle, and Ito (1994), Ng (2000), Climent and Meneu (2003), Sander and Kleimeier (2003)).

Having estimated transition matrices for each model we are able to compute the probabilities of some market entering the state of crisis or calm, conditional on the information that this market and the US market were in their respective states yesterday. These findings are useful in explaining why it is causality but not contagion that usually characterizes intermarket relationships. The empirical results are also of special importance for international investors and the great advantage of the model is that they can be obtained directly using standard computations on the elements of the transition matrix. We additionally provide findings on the probability of one market entering the crisis (calm) regime conditional on the state of the US market one day earlier. The empirical results are presented in Table 4.

Table 4 about here 
The main conclusion from the calculated probabilities is that entering one regime by the market is most likely and even close to one when this market and the US market were in the same regime one period earlier. If the US market was not in that regime one period earlier then the probability of entering the regime by the other market drops in almost all cases. The probability is close to zero that the market enters the state of calm (crisis) when the US market and this respective market were in the opposite regime one period earlier. This finding illustrates how the past information about the US market spills over to other mature markets on the next day. Furthermore, we are able to forecast the future state of the market more accurately having the information about the present state of both markets rather than having the information only about the US market. This in turn explains why the hypothesis of contagion is rejected in our analyses. The past information about each market influences its present performance in such a way that it does not always follow the state of the US market.

We continue the analysis with studying the relations between the markets in the selected three non-overlapping sub-samples to learn how the dependencies between international capital markets change over time. The results from testing all hypotheses of contagion, spillovers, and regime-independence are presented in Table 5. The general findings from this exercise are that the US leads Japan, the UK and Germany, but the patterns of spillovers from the US to those markets vary over time (Rydén, Teräsvirta, and Åsbrink (1998))

Table 5 about here

Some evidence of asymmetry in spillover effects between calm and crisis regimes is present in the investigated sub-samples. In the 1984-1988 period we can accept the 
hypothesis that the S\&P 500 index returns do not lead the DAX and NIKKEI 225 index returns when the latter indices are in the calm regimes. Similarly, from 1996 to 2003 returns on the Japanese market follow the US market returns only in the state of crisis and any spillover effects to Japan are quite weak in this period. The lack of spillovers in any regime to the UK is accepted in the 1989 - 1995 sub-sample. Since regime-independence is also rejected there, we interpret this result as evidence of the inter-dependencies between the US and UK capital markets, which take place without delay. One possible explanation for the lack of spillovers to the UK from the US could be the ERM currency crisis of 1992 that affected most strongly the British market. In the most recent period $1996-2003$, S\&P 500 index returns lead very strongly the DAX returns and one can observe the contagion effect when the German index is in the crisis regime. Likely reasons for this contagion effect could be recent shocks which took place on the US market and spread to other markets after the terrorist attack on September 11 and after the burst of the "dot.com" bubble. In all other cases there are significant spillovers from the US to the other markets independently of the crisis and calm regimes.

From Table 5 one can observe that spillovers between capital markets evolve over time independently of changing regimes. There are naturally some factors other than changing states of the markets which can influence the strength of spillovers and future applications may extend the proposed models by introducing additional elements or varying parameters. Nevertheless, our results show that spillovers between the four big stock capital markets exist in all periods.

There is less evidence of spillovers to the markets in the calm regime than to the stock markets which are in the crisis regime in the sub-periods. This finding could indicate that the market not involved in some international crash often remains resistant to spillovers from the US stock market. As soon as it allows for the high volatility regime at home it becomes more 
vulnerable to the influence of the US market, because concerned investors observe more carefully the performance of the US market in the context of the international turmoil.

This could also suggest that in some periods the analyzed markets are robust to any contagion from the US market, because they enter crisis regimes independently of the US market or simultaneously with the US market. If the latter case was true, then the direction of contagion would be toward the US market rather than from the US market due to possible crises on other not investigated markets that could cause the US market and other analyzed markets to enter the crisis regime in the same time.

Additionally, the US market has less influence on European and Asian markets on the same day because of different trading hours on the stock exchanges in Asia, Europe, and America. American stock markets open and close after the European and Asian markets each day, although some trading hours overlap. In contrast, European and Asian stock index returns may influence the American index returns on the same day (e.g., Cheung and Ng (1996)). Thus, some modifications in data are required to test for spillovers from European or Asian markets to the US market. However, we leave this issue for further research.

\section{Conclusions}

In this article, we investigate international financial spillovers from the US stock market to the Japanese, British, and German markets. We introduce a statistical framework to deal with the problem of asymmetries in financial spillovers in calm and turbulent regimes. Spillovers and contagion to stock markets during crisis and calm periods are explicitly defined and new tests are proposed to distinguish between financial spillovers in crisis and calm regimes.

Our testing framework is capable of distinguishing between different types of relations connecting two stock markets, i.e., contagion, spillovers, and independence. Thus, we compare 
the results from testing financial spillovers with outcomes from the tests of contagion and independence and obtain evidence that the Japanese, British, and German stock markets are dependent on the past performance of the US market, but encounter almost no indication of contagion in the spirit of Sola, Spagnolo, and Spangolo (2002). We find that spillovers taking place when the dependent markets are in the crisis regime are more frequent than spillovers to the markets in the state of calm, which is in line with the results of Chen, Chiang, and So (2003). This result suggests that financial crashes on the US market do not always directly cause turmoil on the Japanese, British, and German stock markets. However, the crashes on the US market increase the probability of a crisis on the three other mature markets, which is in line with the hypothesis of contagious crises introduced by Eichengreen, Rose, and Wyplosz (1996). The finding that less spillovers from the US to other stock markets during calm relative to crisis periods has an implication for an international portfolio diversification strategy due to its lower benefits in turbulent regimes.

Additionally, we present the probabilities for the Japanese, British, and German stock markets individually entering the states of calm and crisis periods, conditional on the information about the past performance of those markets and the US market. Information from both markets is found to be relevant for efficient forecasting of future stock market index returns on those markets, therefore further research could incorporate our framework in testing for diversification benefits from asset allocation on international markets, as in Ang and Bekaert $(2002,2004)$. 


\section{References}

Ang, Andrew and Geert Bekaert (2002), International Asset Allocation with Regime Shifts, The Review of Financial Studies 15, $1137-1187$.

Ang, Andrew and Geert Bekaert (2004), How Do Regimes Affect Asset Allocation?, Financial Analysts Journal 60, $86-99$.

Bae, Kee-Hong, G. Andrew Karolyi, and René Stulz (2003), A New Approach to Measuring Financial Contagion, The Review of Financial Studies 16, $717-763$.

Bekaert, Geert and Campbell R. Harvey (2003), Emerging markets finance, Journal of Empirical Finance 10, 3- 55.

Białkowski, Jędrzej and Dobromił Serwa (2005), Financial contagion, spillovers, and causality in the Markov switching framework, Quantitative Finance 5, 123 - 131.

Billio, Monica and Loriana Pelizzon (2003), Contagion and Interdependence in Stock Markets: Have they been misdiagnosed? Journal of Economics and Business 55, $405-426$.

Black, Fisher (1976), Studies of stock market volatility changes, Proceedings of the American Statistical Association, Business and Economic Statistics Section, 177 - 181.

Breunig, Robert, Serinah Najarian, and Adrian Pagan (2003), Specification Testing of Markov Switching Models, Oxford Bulletin of Economics and Statistics 65, Supplement, 703 725.

Cecchetti, Stephen, Pok-sang Lam, and Nelson Mark (1990), Mean Reversion in Equilibrium Asset Prices, American Economic Review 80, 398 - 418.

Chen, Cathy W. S., Thomas C. Chiang, and Mike K. P. So (2003), Asymmetrical reaction to US stock-return news: evidence from major stock markets based on a double-threshold model, Journal of Economics and Business 55, 487 - 502.

Cheung, Yin-Wong and Lilian K. Ng (1996), A causality-in-variance test and its application to financial market prices, Journal of Econometrics 72, $33-48$.

Claessens, Stijn and Katrin Forbes (eds.) (2001), International Financial Contagion, Kluwer Academic Publishers.

Climent, Francisco J. and Vicente Meneu (2003) Has 1997 Asian Crisis increased Information Flows between International Markets? International Review of Economics and Finance $12,111-143$.

Dornbusch, Rudiger, Yung Chul Park, and Stijn Claessens (2000) Contagion: Understanding How It Spreads, World Bank Research Observer 15, 177 - 197. 
Dungey, Mardi and Diana Zhumabekova (2001), Testing for contagion using correlations: some words of caution, Working Paper No. PB01-09, Pacific Basin Working Paper Series, Federal Reserve Bank of San Francisco.

Edwards, Sebastian and Raul Susmel (2001), Volatility dependence and contagion in emerging equity markets, Journal of Development Economics 66, 505 - 532.

Eichengreen, Barry, Andrew K. Rose, and Charles Wyplosz (1996), Contagion Currency Crises: First Tests, Scandinavian Journal of Economics 98, 463 - 484.

Eun, Cheol S. and Sangdal Shim (1989), International Transmission of Stock Market Movements, Journal of Financial Quantitative Analysis 24, 241 - 256.

Engle, Robert F. and Victor K. Ng (1993), Measuring and testing the impact of news on volatility, Journal of Finance 48, $1749-1778$.

Fontaine, Thomson (2005), Currency Crises in Developed and Emerging Market Economies: A Comparative Empirical Treatment, IMF Working Paper 05/13.

Forbes, Kristin and Roberto Rigobon (2001), Measuring Contagion: Conceptual and Empirical Issues, in: S. Claessens and K. Forbes (eds.), International Financial Contagion, Kluwer Academic, NewYork.

Forbes, Kristin J. and Roberto Rigobon (2002), No Contagion, Only Interdependence: Measuring Stock Market Co-Movements, Journal of Finance 57, 2223 - 2261.

Geweke, John (1984), Inference and causality in economic time series models, in: Z. Griliches and M.D. Intriligator (eds.), Handbook of Econometrics, Elsevier Science Publishers, Volume II, Chapter 19, 1101 - 1144.

Granger, Clive W.J. (1969), Investigating causal relationships by econometric models and cross-spectral methods, Econometrica 37, 424 - 438.

Granger, Clive W.J. (1980), Testing for causality: a personal viewpoint, Journal of Economic Dynamics and Control 2, $329-352$.

Hamao, Yasushi, Ronald Masulis, and Victor Ng (1990), Correlations in Price Changes and Volatility across International Stock Markets, The Review of Financial Studies 3, 281 307.

Hamilton, James D. (1989), A New Approach to the Economic Analysis of Nonstationary Time Series and the Business Cycle, Econometrica 57, 357 - 384.

Hamilton, James D. (1990), Analysis of Time Series Subject to Changes in Regime, Journal of Econometrics, 45, 39-70.

Hamilton, James D. and Gang Lin (1996), Stock Market Volatility and the Business Cycle, Journal of Applied Econometrics 11, 573 - 593. 
Hartmann, Philipp, Stefan Straetmans, and Casper B. de Vries (2004), Asset Market Linkages in Crisis Periods, Review of Economics and Statistics 86, 313 - 326.

Karolyi, G. Andrew (2003), Does International Financial Contagion Really Exist? International Finance 6, $179-199$.

Karolyi, G. Andrew and René M. Stulz (1996), Why Do Markets Move Together? An Investigation of US-Japan Stock Return Co-movements, Journal of Finance 51, 951 986.

King, Mervyn A. and Sushil Wadhwani (1990), Transmission of Volatility between Stock Markets, The Review of Financial Studies 3, 5-33.

Lin, Wen-Ling, Robert F. Engle, and Takatoshi Ito (1994), Do bulls and bears move across borders? International transmission of stock returns and volatility as the world turns, The Review of Financial Studies 7, $507-538$.

Longin, François and Bruno Solnik (2001), Extreme Correlation of International Equity Markets, Journal of Finance 56, $649-676$.

Malliaris, A. G. and Jorge L. Urrutia (1992), The International Crash of October 1987: Causality Tests, Journal of Financial and Quantitative Analysis 27, 353 - 364.

Mishkin, Frederic and Eugene N. White (2003), U.S. Stock Market Crashes and Their Aftermath: Implications for Monetary Policy, in William C. Hunter, George G. Kaufmann, and Michael Pomerleano, eds., Asset Price Bubbles: The Implications for Monetary Regulatory, and International Policies, The MIT Press, 53 - 79.

Moser, Thomas (2003), What Is International Financial Contagion?, International Finance 6, $157-178$

$\mathrm{Ng}$, Angela (2000), Volatility spillover effects from Japan and the US to the Pacific-Basin, Journal of International Money and Finance 19, 207 - 233.

Peiró, Amado, Javier Quesada, and Ezequiel Uriel (1998), Transmission of movements in stock markets, The European Journal of Finance 4, 331 - 343.

Pericoli, Marcello and Massimo Sbracia (2003), A Primer on Financial Contagion, Journal of Economic Surveys 17, $571-608$.

Phillips, Kerk L. (1991), A two-country model of stochastic output with changes in regime, Journal of International Economics 31, 121 - 142.

Psaradakis, Zacharias, Morton O. Ravn, and Martin Sola (2004), Markov Switching Causality and the Money-Output Relationship, Journal of Applied Econometrics, forthcoming.

Ravn, Marten O. and Martin Sola (1995), Stylized facts and regime changes: Are prices procyclical, Journal of Monetary Economics 36, 497 - 526. 
Rigobon, Roberto (2003), Identification Through Heteroscedasticity, Review of Economics and Statistics 85, $777-792$.

Rydén, Tobias, Timo Teräsvirta, and Stefan Åsbrink (1998), Stylized Facts of Daily Return Series and the Hidden Markov Model, Journal of Applied Econometrics 13, 217 - 244.

Sander, Harald and Stefanie Kleimeier (2003), Contagion and Causality: An Empirical Investigation of Four Asian Crisis Episodes, Journal of International Financial Markets, Institutions \& Money 13, $171-186$.

Sola, Martin, Fabio Spagnolo, and Nicola Spagnolo (2002), A test for volatility spillovers, Economics Letters 76, $77-84$.

Turner, Christopher M., Richard Stratz, and Charles R. Nelson (1990), A Markov Model of Heteroskedasticity, Risk and Learning in the Stock Market, Journal of Financial Economics 25, $3-22$. 
Table 1: Log-likelihood Values of the Estimated Markov Switching Models

\begin{tabular}{lccc}
\hline \hline & $\begin{array}{c}\text { S\&P 500 } \\
\text { and } \\
\text { NIKKEI 225 }\end{array}$ & $\begin{array}{c}\text { S\&P 500 } \\
\text { and } \\
\text { FTSE 100 }\end{array}$ & $\begin{array}{c}\text { S\&P 500 } \\
\text { and } \\
\text { DAX }\end{array}$ \\
\hline$L_{\text {SPILLOVERS }}$ & -13222.11 & -11780.00 & -12957.88 \\
$L_{\text {NS IN CRISIS }}$ & -13238.43 & -11834.50 & -12988.96 \\
$L_{\text {NS IN PROSPERITY }}$ & -13235.73 & -11821.00 & -12979.50 \\
$L_{\text {NS }}$ & -13247.70 & -11863.07 & -13006.06 \\
$L_{\text {INDEPENDENCE }}$ & -13390.40 & -11858.60 & -13062.95 \\
$L_{\text {CONTAGION }}$ & -13386.00 & -11840.58 & -13069.87 \\
$L_{\text {CONTAGION IN CRISIS }}$ & -13331.62 & -11816.13 & -13003.45 \\
\hline \hline
\end{tabular}

Note: The log-likelihood values corresponding with the estimates are denoted by $L_{\text {SPILLOVERS }}$ for the general model, $L_{\text {INDEPENDENCE }}$ for the independence model, $L_{\text {CONTAGION }}$ for the contagion model, $L_{\text {CONTAGION IN CRISIS }}$ for the "contagion during crises" model, and $L_{N S}$, $L_{\text {NS IN CRISIS }}, L_{\text {NS IN PROSPERITY }}$ for the no-spillover models with the transition matrices (23), (24), and (22), respectively. 
Table 2: Tests of Linkages between the Markets

\begin{tabular}{lccc}
\hline \hline $\begin{array}{l}\text { Null hypothesis } \\
\text { NIKKEI 225 }\end{array}$ & $\begin{array}{c}\text { S\&P 500 } \\
\text { and } \\
\text { Regime- } \\
\text { independence }\end{array}$ & $\begin{array}{c}\text { S\&P 500 } \\
\text { and }\end{array}$ & $\begin{array}{c}\text { S\&P 500 } \\
\text { and } \\
\text { DAX }\end{array}$ \\
\hline $\begin{array}{l}\text { No spillovers } \\
\text { during calm }\end{array}$ & $26.64^{* *}$ & $82.00^{* * *}$ & $43.24 * *$ \\
\hline $\begin{array}{l}\text { No spillovers } \\
\text { during crises }\end{array}$ & $33.24^{* *}$ & $109.00^{* *}$ & $62.16^{* *}$ \\
\hline $\begin{array}{l}\text { No spillovers at } \\
\text { any regimes }\end{array}$ & $51.18^{* *}$ & $127.19^{* *}$ & $96.36^{* *}$ \\
\hline $\begin{array}{l}\text { Contagion } \\
\text { Contagion during } \\
\text { crises }\end{array}$ & $327.78^{* *}$ & $121.16^{* * *}$ & $223.98^{* *}$ \\
\hline \hline $\begin{array}{l}\text { Note: } * \text { and ** denote rejection of the null hypothesis at the 5\% and 1\% } \\
\text { levels, respectively. }\end{array}$ & & \\
\hline
\end{tabular}


Table 3: Final Models of Dependencies between the Markets

\begin{tabular}{|c|c|c|c|c|c|c|c|c|c|c|}
\hline State of $X$ & State of $Y$ & $\begin{array}{l}\mu^{X} \\
(\%)\end{array}$ & $\begin{array}{l}\sigma^{X} \\
(\%)\end{array}$ & $\begin{array}{c}\mu^{Y} \\
(\%)\end{array}$ & $\begin{array}{c}\sigma^{Y} \\
(\%)\end{array}$ & $\operatorname{corr}(X, Y)$ & \multicolumn{4}{|c|}{ Transition matrix $P$} \\
\hline \multicolumn{11}{|l|}{ S\&P 500} \\
\hline calm & Calm & $\begin{array}{c}0.080 \\
(0.007)\end{array}$ & $\begin{array}{c}0.670 \\
(0.023)\end{array}$ & $\begin{array}{c}0.107 \\
(0.013)\end{array}$ & $\begin{array}{c}0.845 \\
(0.035)\end{array}$ & $\begin{array}{c}0.175 \\
(0.066)\end{array}$ & 0.982 & 0.002 & 0.001 & 0.015 \\
\hline calm & crisis & $\begin{array}{c}0.080 \\
(0.007)\end{array}$ & $\begin{array}{c}5.944 \\
(1.891)\end{array}$ & $\begin{array}{c}0.019 \\
(0.001)\end{array}$ & $\begin{array}{c}4.994 \\
(1.044)\end{array}$ & $\begin{array}{c}0.315 \\
(0.092)\end{array}$ & 0.000 & 0.566 & 0.043 & 0.391 \\
\hline crisis & calm & $\begin{array}{c}0.037 \\
(0.004)\end{array}$ & $\begin{array}{c}1.842 \\
(0.495)\end{array}$ & $\begin{array}{c}0.107 \\
(0.013)\end{array}$ & $\begin{array}{c}3.007 \\
(0.747)\end{array}$ & $\begin{array}{c}0.684 \\
(0.171)\end{array}$ & 0.000 & 0.000 & 0.972 & 0.028 \\
\hline crisis & crisis & $\begin{array}{c}0.037 \\
(0.004) \\
\end{array}$ & $\begin{array}{c}1.127 \\
(0.297)\end{array}$ & $\begin{array}{c}0.019 \\
(0.001) \\
\end{array}$ & $\begin{array}{c}1.493 \\
(0.444) \\
\end{array}$ & $\begin{array}{c}0.378 \\
(0.092) \\
\end{array}$ & 0.025 & 0.007 & 0.005 & 0.962 \\
\hline \multicolumn{11}{|l|}{ S\&P 500} \\
\hline calm & calm & $\begin{array}{c}0.082 \\
(0.006)\end{array}$ & $\begin{array}{c}0.666 \\
(0.084)\end{array}$ & $\begin{array}{c}0.065 \\
(0.005)\end{array}$ & $\begin{array}{c}0.732 \\
(0.091)\end{array}$ & $\begin{array}{c}0.315 \\
(0.024)\end{array}$ & 0.978 & 0.000 & 0.022 & 0.000 \\
\hline calm & crisis & $\begin{array}{c}0.082 \\
(0.006)\end{array}$ & $\begin{array}{c}8.717 \\
(2.110)\end{array}$ & $\begin{array}{r}-0.088 \\
(0.007)\end{array}$ & $\begin{array}{c}5.250 \\
(1.417)\end{array}$ & $\begin{array}{c}0.493 \\
(0.067)\end{array}$ & 0.000 & 0.513 & 0.382 & 0.105 \\
\hline crisis & calm & $\begin{array}{c}-0.064 \\
(0.009)\end{array}$ & $\begin{array}{c}1.222 \\
(0.195)\end{array}$ & $\begin{array}{c}0.065 \\
(0.005)\end{array}$ & $\begin{array}{c}1.138 \\
(0.214)\end{array}$ & $\begin{array}{c}0.444 \\
(0.072)\end{array}$ & 0.035 & 0.005 & 0.953 & 0.007 \\
\hline crisis & Crisis & $\begin{array}{r}-0.064 \\
(0.009)\end{array}$ & $\begin{array}{c}1.946 \\
(0.280) \\
\end{array}$ & $\begin{array}{r}-0.088 \\
(0.007)\end{array}$ & $\begin{array}{c}2.174 \\
(0.540) \\
\end{array}$ & $\begin{array}{c}0.517 \\
(0.091) \\
\end{array}$ & 0.000 & 0.000 & 0.037 & 0.963 \\
\hline \multicolumn{11}{|l|}{ S\&P 500} \\
\hline calm & calm & $\begin{array}{c}0.099 \\
(0.010)\end{array}$ & $\begin{array}{c}0.738 \\
(0.135)\end{array}$ & $\begin{array}{c}0.099 \\
(0.095)\end{array}$ & $\begin{array}{c}0.640 \\
(0.140)\end{array}$ & $\begin{array}{c}0.066 \\
(0.009)\end{array}$ & 0.970 & 0.014 & 0.000 & 0.016 \\
\hline calm & crisis & $\begin{array}{r}0.099 \\
(0.010)\end{array}$ & $\begin{array}{c}0.637 \\
(0.102)\end{array}$ & $\begin{array}{r}-0.027 \\
(0.012)\end{array}$ & $\begin{array}{c}1.659 \\
(0.342)\end{array}$ & $\begin{array}{c}0.154 \\
(0.033)\end{array}$ & 0.016 & 0.969 & 0.008 & 0.007 \\
\hline crisis & calm & $\begin{array}{r}-0.005 \\
(0.002)\end{array}$ & $\begin{array}{c}3.066 \\
(0.980)\end{array}$ & $\begin{array}{c}0.099 \\
(0.095)\end{array}$ & $\begin{array}{c}3.289 \\
(0.917)\end{array}$ & $\begin{array}{c}0.142 \\
(0.024)\end{array}$ & 0.000 & 0.057 & 0.850 & 0.092 \\
\hline crisis & crisis & $\begin{array}{r}-0.005 \\
(0.002)\end{array}$ & $\begin{array}{c}1.234 \\
(0.123)\end{array}$ & $\begin{array}{r}-0.027 \\
(0.012)\end{array}$ & $\begin{array}{c}1.363 \\
(0.202)\end{array}$ & $\begin{array}{c}0.176 \\
(0.053)\end{array}$ & 0.017 & 0.000 & 0.018 & 0.965 \\
\hline
\end{tabular}

Note: For further explanations see text. 
Table 4: Probability of a Crisis or Calm Today and the Information from Yesterday

\begin{tabular}{lccc}
\hline \hline$X$ represents the S\&P 500 index returns and $Y$ represents: & NIKKEI 225 & FTSE 100 & DAX \\
\hline \multicolumn{1}{c}{ Probabilities conditional on the information from $X_{t-1}$ and $Y_{t-1}$} & \\
\hline $\operatorname{Pr}\left(Y_{t}\right.$ in calm $\mid Y_{t-1}$ in calm and $X_{t-1}$ in calm $)$ & 0.970 & 1.000 & 0.983 \\
$\operatorname{Pr}\left(Y_{t}\right.$ in calm $\mid Y_{t-1}$ in calm and $X_{t-1}$ in crisis $)$ & 0.850 & 0.988 & 0.972 \\
\hline $\operatorname{Pr}\left(Y_{t}\right.$ in calm $\mid Y_{t-1}$ in crisis and $X_{t-1}$ in calm $)$ & 0.024 & 0.382 & 0.043 \\
$\operatorname{Pr}\left(Y_{t}\right.$ in calm $\mid Y_{t-1}$ in crisis and $X_{t-1}$ in crisis $)$ & 0.035 & 0.037 & 0.030 \\
\hline $\operatorname{Pr}\left(Y_{t}\right.$ in crisis $\mid Y_{t-1}$ in calm and $X_{t-1}$ in calm $)$ & 0.030 & 0.000 & 0.017 \\
$\operatorname{Pr}\left(Y_{t}\right.$ in crisis $\mid Y_{t-1}$ in calm and $X_{t-1}$ in crisis $)$ & 0.150 & 0.012 & 0.028 \\
\hline $\operatorname{Pr}\left(Y_{t}\right.$ in crisis $\mid Y_{t-1}$ in crisis and $X_{t-1}$ in calm $)$ & 0.976 & 0.618 & 0.957 \\
$\operatorname{Pr}\left(Y_{t}\right.$ in crisis $\mid Y_{t-1}$ in crisis and $X_{t-1}$ in crisis $)$ & 0.965 & 0.963 & 0.970 \\
\hline \multicolumn{2}{|}{ Probabilities conditional only on the information from $X_{t-1}$} & \\
\hline $\operatorname{Pr}\left(Y_{t}\right.$ in calm $\mid X_{t-1}$ in calm $)$ & 0.564 & 0.929 & 0.967 \\
$\operatorname{Pr}\left(Y_{t}\right.$ in calm $\mid X_{t-1}$ in crisis $)$ & 0.149 & 0.206 & 0.231 \\
\hline $\operatorname{Pr}\left(Y_{t}\right.$ in crisis $\mid X_{t-1}$ in calm $)$ & 0.436 & 0.071 & 0.033 \\
$\operatorname{Pr}\left(Y_{t}\right.$ in crisis $\mid X_{t-1}$ in crisis $)$ & 0.851 & 0.794 & 0.769 \\
\hline \hline
\end{tabular}

Note: For further explanations see text. 
Table 5: Tests of Linkages between the Markets in Sub-Samples

\begin{tabular}{|c|c|c|c|c|}
\hline Sub-periods & Null hypothesis & $\begin{array}{c}\text { S\&P 500 } \\
\text { and } \\
\text { NIKKEI } 225\end{array}$ & $\begin{array}{l}\text { S\&P } 500 \\
\text { and } \\
\text { FTSE } 100\end{array}$ & $\begin{array}{c}\text { S\&P } 500 \\
\text { and } \\
\text { DAX }\end{array}$ \\
\hline \multirow[t]{6}{*}{$1984 / 04 / 03-1988 / 12 / 28$} & $\begin{array}{l}\text { Regime- } \\
\text { independence }\end{array}$ & $93.18 * *$ & $53.12 * *$ & $63.24 * *$ \\
\hline & $\begin{array}{l}\text { No spillovers } \\
\text { during calm }\end{array}$ & 3.20 & $7.23 * *$ & 0.94 \\
\hline & $\begin{array}{l}\text { No spillovers } \\
\text { during crises }\end{array}$ & $7.02 * *$ & $15.77 * *$ & $4.28^{*}$ \\
\hline & $\begin{array}{l}\text { No spillovers at } \\
\text { any regimes }\end{array}$ & $53.24 * *$ & $25.52 * *$ & 4.52 \\
\hline & Contagion & $105.38 * *$ & $87.82 * *$ & $66.42 * *$ \\
\hline & $\begin{array}{l}\text { Contagion during } \\
\text { crises }\end{array}$ & $22.58 * *$ & $71.88^{* *}$ & $61.88 * *$ \\
\hline \multirow[t]{6}{*}{$1989 / 01 / 04-1995 / 12 / 29$} & $\begin{array}{l}\text { Regime- } \\
\text { independence }\end{array}$ & $61.98 * *$ & $56.96^{* *}$ & $65.00 * *$ \\
\hline & $\begin{array}{l}\text { No spillovers } \\
\text { during calm }\end{array}$ & $8.96 * *$ & 1.16 & $9.42 * *$ \\
\hline & $\begin{array}{l}\text { No spillovers } \\
\text { during crises }\end{array}$ & $19.14 * *$ & 2.76 & $24.04 * *$ \\
\hline & $\begin{array}{l}\text { No spillovers at } \\
\text { any regimes }\end{array}$ & $25.98 * *$ & 5.84 & $37.42 * *$ \\
\hline & Contagion & $56.14 * *$ & $71.30 * *$ & $61.24 * *$ \\
\hline & $\begin{array}{l}\text { Contagion during } \\
\text { crises }\end{array}$ & $40.58 * *$ & $56.02 * *$ & $31.52 * *$ \\
\hline \multirow[t]{6}{*}{$1996 / 01 / 04-2003 / 05 / 30$} & $\begin{array}{l}\text { Regime- } \\
\text { independence }\end{array}$ & $94.56 * *$ & $112.26^{* *}$ & $95.46^{* *}$ \\
\hline & $\begin{array}{l}\text { No spillovers } \\
\text { during calm }\end{array}$ & 3.00 & $12.48 * *$ & $8.82 * *$ \\
\hline & $\begin{array}{l}\text { No spillovers } \\
\text { during crises }\end{array}$ & $5.86^{*}$ & $23.04 * *$ & $11.80 * *$ \\
\hline & $\begin{array}{l}\text { No spillovers at } \\
\text { any regimes }\end{array}$ & $7.76^{*}$ & $56.64 * *$ & $20.90 * *$ \\
\hline & Contagion & $41.94 * *$ & $42.68 * *$ & $24.04 * *$ \\
\hline & $\begin{array}{l}\text { Contagion during } \\
\text { crises }\end{array}$ & $28.96 * *$ & $27.30 * *$ & 9.14 \\
\hline
\end{tabular}

Note: $*$ and $* *$ denote rejection of the null hypothesis at the $5 \%$ and $1 \%$ levels. respectively. 
Figure 1: The Financial Spillovers Hypotheses and Their Testing Sequence

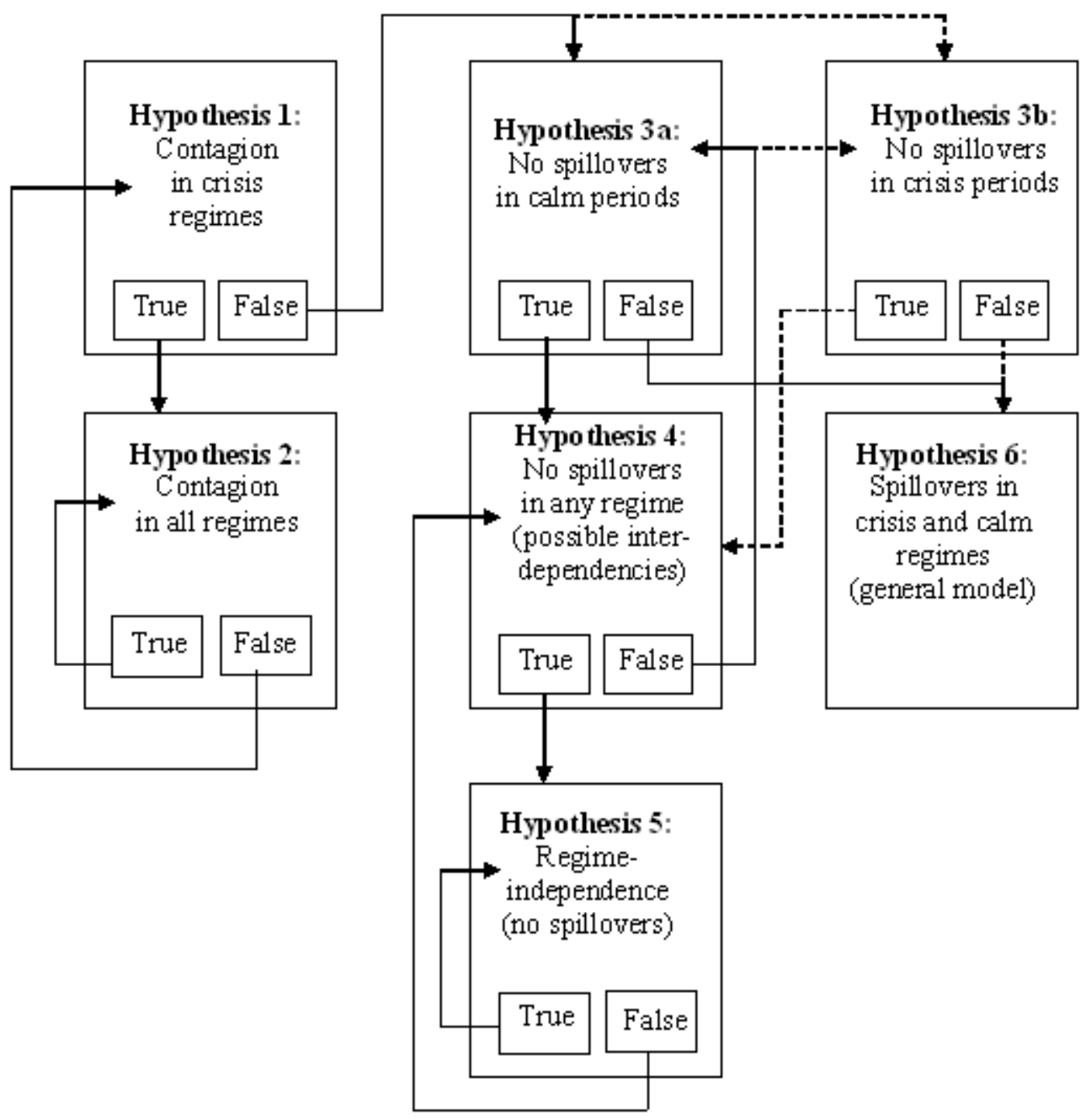




\section{Appendix}

Table A1: Specification Tests for the Estimated Markov Switching Models

\begin{tabular}{|c|c|c|c|}
\hline Null hypothesis & $\begin{array}{c}\text { S\&P } 500(X) \\
\text { and } \\
\text { NIKKEI } 225(Y) \\
\end{array}$ & $\begin{array}{l}\text { S\&P } 500(X) \\
\text { and } \\
\text { FTSE } 100(Y)\end{array}$ & $\begin{array}{c}\text { S\&P } 500(X) \\
\text { and } \\
\operatorname{DAX}(Y) \\
\end{array}$ \\
\hline$\mu_{S}^{X}=\mu_{D}^{X}$ & $\begin{array}{c}0.122 \\
{[0.9030]}\end{array}$ & $\begin{array}{c}-0.653 \\
{[0.5138]}\end{array}$ & $\begin{array}{c}-0.293 \\
{[0.7694]}\end{array}$ \\
\hline$\mu_{S}^{Y}=\mu_{D}^{Y}$ & $\begin{array}{c}-0.420 \\
{[0.6748]}\end{array}$ & $\begin{array}{c}0.670 \\
{[0.5026]}\end{array}$ & $\begin{array}{c}-0.498 \\
{[0.6182]}\end{array}$ \\
\hline$\sigma_{S}^{X}=\sigma_{D}^{X}$ & $\begin{array}{c}1.02 \\
{[0.5191]}\end{array}$ & $\begin{array}{c}0.99 \\
{[0.7629]}\end{array}$ & $\begin{array}{c}1.01 \\
{[0.6949]}\end{array}$ \\
\hline$\sigma_{S}^{Y}=\sigma_{D}^{Y}$ & $\begin{array}{c}0.98 \\
{[0.5769]}\end{array}$ & $\begin{array}{c}1.02 \\
{[0.4323]}\end{array}$ & $\begin{array}{c}0.99 \\
{[0.6369]}\end{array}$ \\
\hline Leverage $_{S}^{X}=$ Leverage $_{D}^{X}$ & $\begin{array}{c}0.044 \\
{[0.9647]}\end{array}$ & $\begin{array}{c}0.358 \\
{[0.7203]}\end{array}$ & $\begin{array}{c}0.167 \\
{[0.8677]}\end{array}$ \\
\hline Leverage $_{S}^{Y}=$ Leverage $_{D}^{Y}$ & $\begin{array}{c}0.588 \\
{[0.5568]}\end{array}$ & $\begin{array}{c}0.820 \\
{[0.4121]}\end{array}$ & $\begin{array}{c}0.067 \\
{[0.9469]}\end{array}$ \\
\hline $\operatorname{Peak}_{S}^{X}=$ Peak $_{D}^{X}$ & $\begin{array}{l}-1.036 \\
{[0.3003]}\end{array}$ & $\begin{array}{c}0.316 \\
{[0.7523]}\end{array}$ & $\begin{array}{c}-0.940 \\
{[0.3473]}\end{array}$ \\
\hline $\operatorname{Peak}_{S}^{Y}=\operatorname{Peak}_{D}^{Y}$ & $\begin{array}{c}-0.765 \\
{[0.4445]}\end{array}$ & $\begin{array}{c}-0.518 \\
{[0.6046]}\end{array}$ & $\begin{array}{c}-0.936 \\
{[0.3493]}\end{array}$ \\
\hline
\end{tabular}

Note: The symbols $D$ and $S$ denote the original and simulated data, respectively. P-values are presented in squared parentheses under the values of test statistics. $*$ and $* *$ denote rejection of the null hypothesis at the $10 \%$ and $5 \%$ levels, respectively. 